\section{Miradas feministas en el cine contemporáneo}

Feminism Discourses in Contemporary Cinema

\author{
Fabiola Alcalá Anguiano \\ f.alcala79@gmail.com
}

https://orcid.org/0000-0002-1200-280X

Fanny Cervantes González cervantesfanny@outlook.com

Universidad de Guadalajara, México.

FECHA DE RECEPCIÓN marzo 4, 2020

FECHA DE APROBACIÓN abril 21, 2020

FECHA DE PUBLICACIÓN julio 1, 2020

https://doi.org/10.32870/ elojoquepiensa.v0i21.353
Resumen / Este artículo pretende analizar tres películas contemporáneas protagonizadas por mujeres

- Las estafadoras (2018), Be Natural: The Untold Story of Alice Guy-Blaché (2018) y El camino soñado (2016) - con el fin de ilustrar tres tipos de discursos o miradas feministas y constatar, a través de estas posturas teórico-ideológicas, si la representación de la mujer en estos filmes contribuye a la consolidación de la igualdad de género. Así mismo, se abordará la relación entre el cine y el feminismo, la cual ha dado lugar a la producción de importantes aportes teóricos que servirán como marco de referencia en este texto.

Palabras clave / feminismo, cine de mujeres, igualdad de género.
Abstract / This article aims to analyze three contemporary films starring women -Ocean's 8 (2018), Be Natural: The Untold Story of Alice Guy-Blaché (2018) and The Dreamed Path (2016) - in order to illustrate three types of three types of feminism discourses and verify, through these theoretical-ideological positions, if the representation of women in these films contribute to the consolidation of gender equality. Likewise, the relationship between cinema and feminism will be addressed, which has resulted in the production of important theoretical contributions that will serve as a frame of reference in this text.

KeYWORDS / feminism, women's cinema, gender equality. 
que complejizan los feminismos en plural. De ahí que en el terreno del análisis feminista en ocasiones se ve como algo necesario matizar desde qué postura se está hablando, porque habrá productos o fenómenos socioculturales que desde una perspectiva sean más o menos correctos que desde otra.

En el cine contemporáneo, por ejemplo, se puede advertir una tendencia a ver más mujeres e historias sobre ellas en pantalla, pero ¿se puede hablar de cine feminista? Y de ser así, ¿de qué tipo? ¿Cuál es el discurso que prevalece? ¿Sustituir héroes por heroínas abona del todo al terreno de la igualdad de género?

Así mismo, cabe cuestionarse si la mayoría de los filmes en los que participan y se representan mujeres, producidos dentro del cine hegemónico e industrial, como lo llaman Marta Selva y Anna Solá (2002), contribuyen a la visualización de una experiencia creativa diferente, en la que influye la pertenencia a un sexo y género distinto al dominante, histórica y culturalmente; y si dichas películas abonan a la creación de nuevas estéticas en que los arquetipos de género sean inoperantes y, como consecuencia de esto, se requieran nuevos lenguajes que revelen la naturaleza de los conflictos sociales e individuales, tal como se propone dentro del llamado cine de mujeres (Selva y Solá, 2002).

Las preguntas anteriores resultan relevantes porque ponen de manifiesto la complejidad del tema de género y el valor que la representación de lo femenino tiene en la pantalla y por ende, en la cultura, pues se parte del supuesto de que:

El cine contribuye a la formación, mantenimiento o eliminación de estereotipos, según apoyen o no las creencias aceptadas socialmente. Además, genera modelos que influyen en la creación de la identidad social. Modelos que pueden ser interpretados como un espejo donde se refleja la cultura de un país, y la matriz en la que aquella se forma y se transforma (Gila y Guil, 1999, p. 89).

Por lo que este texto pretende reflexionar sobre la mujer en la pantalla cinematográfica a través del análisis de tres películas del cine contemporáneo que podrían ilustrar los principales tipos de discursos o miradas feministas que se han desarrollado a lo largo de la historia: feminismo liberal, feminismo radical y feminismos en plural, para con ello problematizar cómo se representa a la mujer en nuestros días y qué implicaciones tienen este tipo de representaciones dentro de la igualdad de género y sus diferentes posturas teórico-ideológicas.

Los filmes seleccionados para dicho análisis son Las estafadoras (Ocean's 8, Gary Ross, 2018), Be Natural: The Untold Story of Alice Guy-Blaché (Pamela B. Green, 2018) y El camino soñado (Der traumhafte Weg, Angela Schanelec, 2016). Estos proceden de distintas tradiciones: el primero es claramente un ejemplo hollywoodense, el segundo una pieza documental, y el tercero un ejemplo de cine nacional, en este caso, alemán. La diversidad de filmes permite reconocer cómo a pesar de ser películas en las que se cuentan historias de mujeres y que se estrenaron en el mismo año, no por fuerza hablan de la misma manera sobre ellas.

\section{Cine y feminismo}

La relación entre el cine y la mujer ha arrojado grandes aportes teóricos. El primero, sin duda, es el de Laura Mulvey, quien fue una de las pioneras de los estudios sobre cine feminista. Ella afirma que el cine de Hollywood está hecho para el espectador masculino y esto coloca a los personajes femeninos en el lugar de objetos de deseo: personajes que están ahí para ser mirados y contemplados por ellos. En palabras de Mulvey (2001):

En un mundo ordenado por el desequilibrio sexual, el placer de mirar se ha escindido entre activo/masculino y pasivo/femenino. La mirada determinante del varón proyecta su fantasía sobre la figura femenina, a la que talla a su medida y conveniencia. En su tradicional papel de objeto de exhibición, las mujeres son contempladas y mostradas simultáneamente con una apariencia codificada para producir un impacto visual y 
erótico tan fuerte, que puede decirse de ellas que connotan 'para-ser-mirabilidad'. La mujer expuesta como objeto sexual es el leitmotiv del espectáculo erótico: desde los pin-ups hasta el striptease, desde Ziegfeld hasta Busby Berkeley, ella significa el deseo masculino, soporta su mirada y actúa para él. Las películas que siguen la tendencia cinematográfica dominante combinan hábilmente espectáculo y narración. La presencia de la mujer es un elemento indispensable del espectáculo en el cine narrativo convencional, aunque su presencia visual tiende a operar en contra del desarrollo del hilo argumental, al congelar el flujo de la acción en momentos de contemplación erótica (p. 370).

En esa misma línea, el trabajo de Annette Kuhn será de suma importancia al organizar los estudios sobre cine feminista reconociendo en ellos la posibilidad de cambio social. Su propuesta implica que en la construcción de género hay una intención política que puede llevar a la acción:

Si se acepta que 'lo cultural' puede subsumirse en la ideología y de este modo considera que tiene efectos en la constitución del sistema sexo/género en cualquier momento de la historia, entonces se vuelve posible afirmar que las intervenciones en el campo de la cultura tienen cierto potencial independiente para transformar los sistemas sexo/género. En otras palabras, 'la lucha cultural' se convierte en una posibilidad política (Kuhn, 1991, p. 19).

Tomando en cuenta estas dos ideas: la primera, que la mujer en el cine tiende a representarse como objeto, y la segunda, que cada que se decide sumarse a la objetivación - o rechazarla - implica un posicionamiento político, es que se articulará el siguiente recorrido. Se revisarán tres filmes protagonizados por mujeres ya mencionados, que podrían servir de ejemplo de las principales miradas feministas y se buscarán las características de las mujeres que los protagonizan, así como los discursos feministas que estén implícitos en dichas características. Cabe señalar que la crítica ha nombrado feministas a estas tres películas por razones diferentes y parte de este trabajo es responder en qué medida lo son o no lo son.

\section{REMAKES DE HOLLYWOOD: ELLAS EN LUGAR DE ELLOS}

Las estafadoras podría considerase un remake de La gran estafa (Ocean's Eleven, Steven Soderbergh, 2001) o bien una secuela más, puesto que la protagonista en esta ocasión es la hermana de Danny Ocean, Debbie. El argumento central es muy parecido a la original: un robo que requiere un equipo especializado - cada una es la mejor en su área- y una mente maestra, que además de buscar el botín pretende resolver asuntos con su expareja. En esta película, el equipo estará conformado solo por mujeres porque, tal como la protagonista afirma, "ellos se hacen notar y nosotras no".

Se trata de una historia de mujeres que juntas se convierten en un equipo infalible para robar un collar Cartier con valor de 150 millones de dólares en la famosa Gala del Met, junto con otros tesoros del lugar. Es importante señalar que cada una sustituye a uno de los ladrones de la película anterior, incluso repiten, además de habilidades o áreas de experticia, rasgos físicos y hasta origen étnico [FIGURAS 1 y 2].

Visto desde la óptica de género podría resultar una propuesta atractiva en el terreno del feminismo liberal, puesto que muestra mujeres inteligentes capaces de crear suspenso y acción en pantalla, un lugar casi siempre ocupado por hombres. Sin embargo, bajo un análisis más radical o plural, se encuentran algunos elementos que todavía requieren un tratamiento mayor en cuestiones de igualdad y perpetuación de estereotipos tradicionales o, como afirmaba Mulvey (2001), de seguir utilizando a los personajes femeninos como parte del espectáculo más que de la trama en sí.

Por ejemplo, Debbie, el personaje principal, deja claro desde la primera escena que actúa como "mujer convencional", pero rebasa el estereotipo. Esto se hace evidente en su evaluación, cuando explica sollozando por qué debería obtener la libertad condicional y culpa de su detención al hecho de enamorarse de la persona equivocada. En la siguiente 

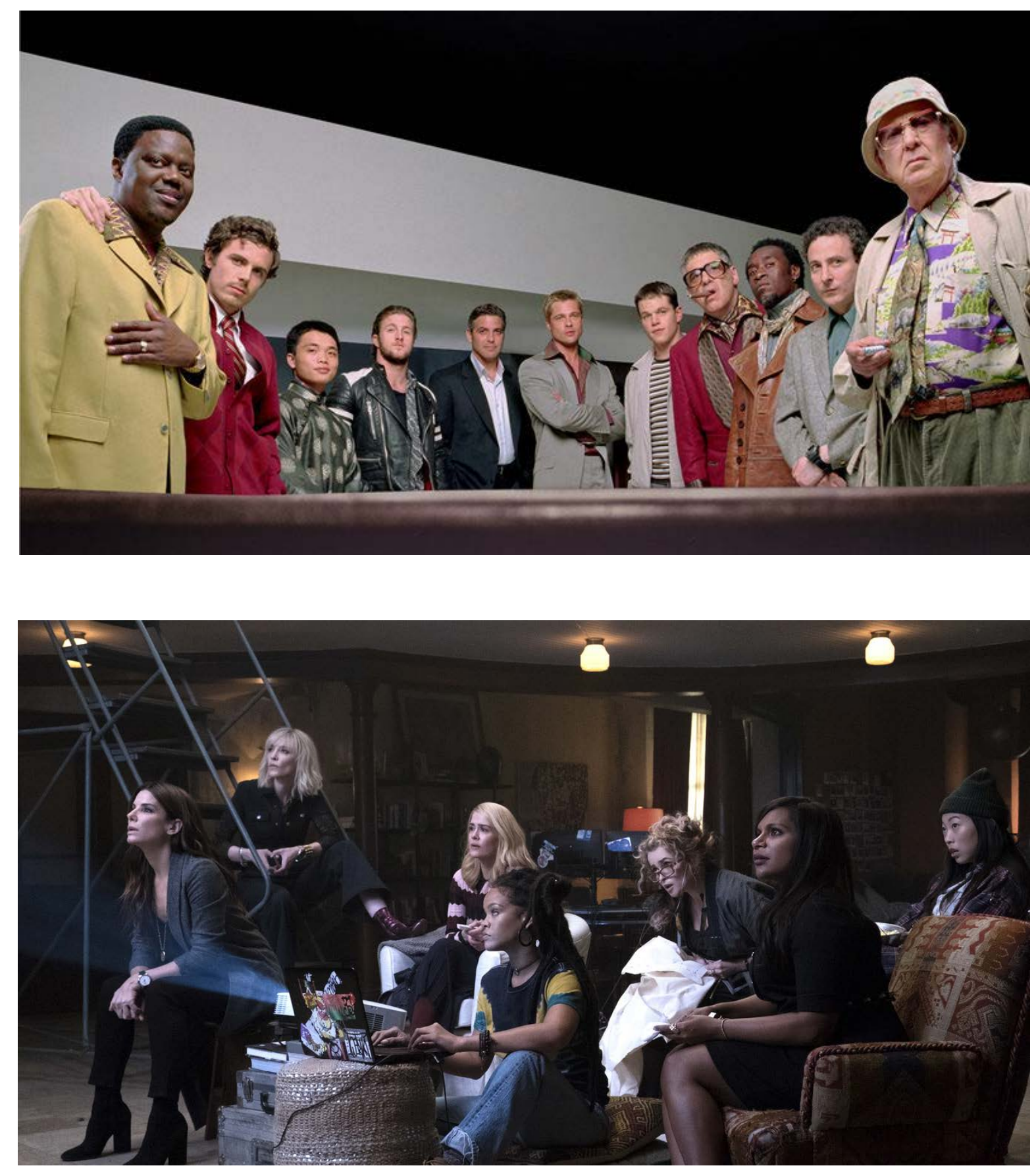

FIGURAS 1 y 2. Ellos y ellas

(La gran estafa, Ocean's Eleven, Steven Soderbergh, 2001;

Las estafadoras, Ocean's 8 , Gary Ross, 2018). 
es totalmente opuesta: el hecho de que Danny vaya a recuperar a su exesposa valiéndose del atraco es visto como un acto heroico, como parte de la recompensa, pues después de robar al actual marido de su mujer, también se la lleva a ella. No obstante, en el caso de Debbie no hay recompensa, ni tampoco heroicidad, solo un acto de venganza, lo cual resta valor a su capacidad como estratega y ladrona [FIGURAs 3 y 4].

En ese mismo sentido, se podría leer como un acierto respecto al tema de la diversidad sexual la inclusión de un personaje gay como Lou. Aunque también suscita preguntas: ¿su gusto por los motores no es también abonar al estereotipo? Se muestra siempre ojeando revistas de autos y cruzando carreteras. ¿Es necesario masculinizar a un personaje femenino homosexual? ¿No es posible otro tipo de representación? ¿Por qué no quedarse con la escena en la que claramente coquetea con Debbie en la cafetería ofreciéndole un trozo de pastel? El gesto es tan sutil que no parece necesitar nada más [FIGURA 5].

Los personajes secundarios también se alejan del feminismo plural, pues son mujeres de distintos grupos étnicos las que hacen el trabajo sucio en el robo. Por ejemplo, la chica que debe arrastrarse para cerrar por dentro la puerta del baño durante el plan es Constance, de ascendencia oriental; la que hace de lavaplatos para infiltrarse a la gala es Amita, de origen indio, quien además aspira a tener un novio como parte de este cierre romántico perfecto. Ella es una experta en joyas que, cuando no está haciendo su trabajo, busca novio en Tinder. Este gesto revela cómo en este ejercicio en equipo las jerarquías parecen estar organizadas por el color de la piel: las mujeres blancas son las líderes y las de otros orígenes étnicos son las de menor rango [FIGURAs 6 y 7].

La Asociación para los Derechos de la Mujer y el Desarrollo (AWID) ilustra cómo desde los feminismos en plural se deben tomar en cuenta estas diferencias:

Por ejemplo, la experiencia de una mujer negra en Ciudad del Cabo es cualitativamente distinta a la de una mujer blanca o indígena en esa misma ciudad. De manera similar, son únicas y distintas las experiencias que implican ser lesbiana, anciana, discapacitada, pobre, del hemisferio norte, y/u otra serie de identidades. El análisis interseccional plantea que no debe-
FIGURA 5. Masculinización de Lou (Las estafadoras, Ocean's 8 , Gary Ross, 2018).

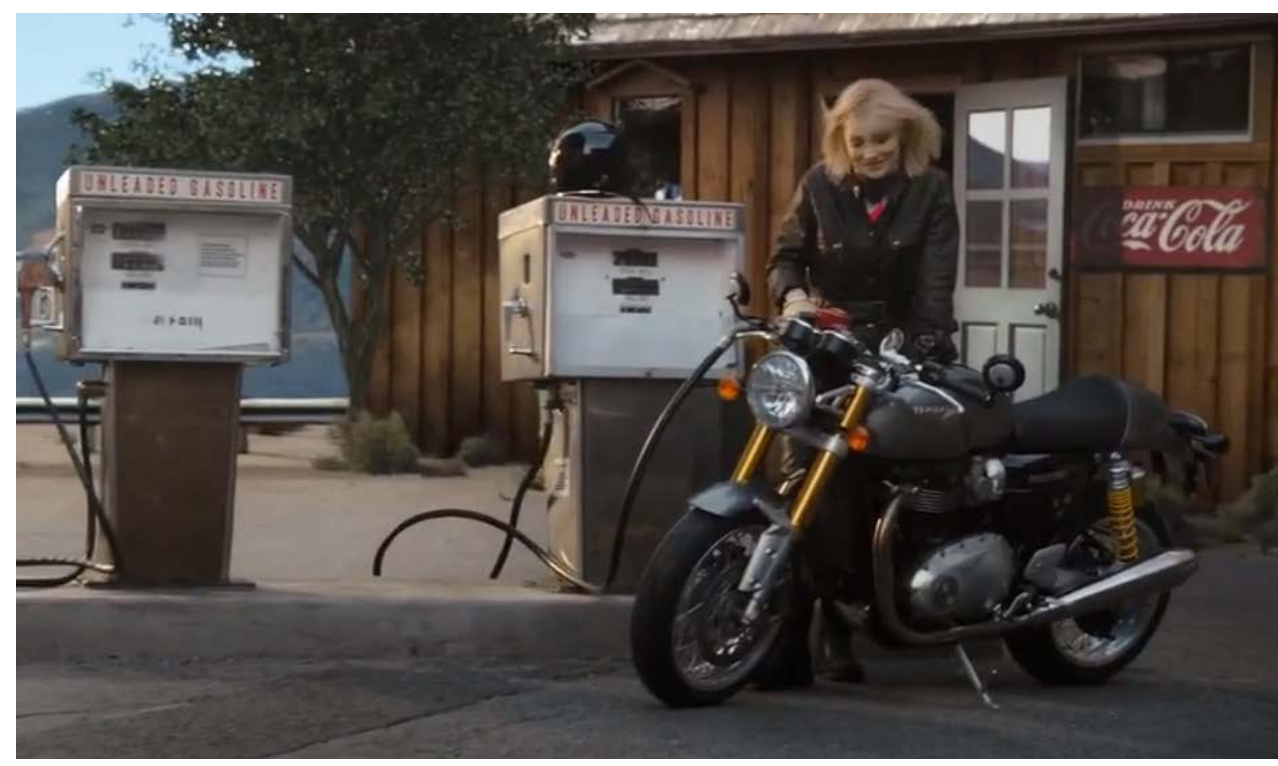

ZOOM OUT /43 
ha contribuido principalmente de dos maneras: la primera, contando historias desde el punto de vista de ellas y para el deleite de ellas, y la segunda, desempolvando historias olvidadas, precisamente para visibilizar la relevancia de las grandes figuras femeninas que frecuentemente se desdibujan. Es el caso del filme Be Natural: The Untold Story

\section{of Alice Guy-Blaché.}

Es un filme documental dirigido por Pamela B. Green en el que se cuenta la historia de la primera cineasta, productora y guionista encargada de llevar la ficción al cine, misma que los libros de historia han dejado en el olvido: Alice Guy-Blaché. La película se vale de distintos recursos para ser contada: animaciones, entrevistas a cineastas, historiadores o teóricos, una entrevista a la propia Alice (filmada en 1964), material de archivo, y algunas de sus películas. En ella se explica cómo esta cineasta ayudó con sus experimentos a la consolidación del lenguaje cinematográfico [FIGURAS 8,9 y 10], como señalan Selva y Solá (2002):

El caso de Alice G. resulta emblemático, sumado al de otras y otros autores cinematográficos, de su paralelo o casi primordial interés por el desarrollo narrativo. Sus 'inventos' en el coloreado y la búsqueda de la sincronía sonora nos habla también de un interés tecnológico que ha sido asimismo negado como relativo a las mujeres (p. 21).

El filme en sí mismo es reivindicativo de la figura olvidada de Guy-Blaché, lo cual alude a un fenómeno que se observa en casi todas las artes: los nombres asociados a los grandes movimientos suelen ser siempre masculinos y eso no significa que no hubiera mujeres trabajando a la par que ellos. El gesto de visibilización es un acto político que invita a cuestionar la historia y a preguntarse por qué se dejan fuera a las mujeres que contribuyeron en esta cuando su participación es importante, incluso más que la de ellos [FIGURA 11].

Además del argumento central y del acto político de visibilizar lo invisible, la película muestra la mirada de la artista, ya que en los pocos filmes que se conservan realizados por ella se puede ver su interés por contar historias en las que lo femenino tiene una gran presencia. Un ejemplo de esto es la pieza Las consecuencias del feminismo (Les résultats du féminisme, 1906) que retrata en clave de humor qué pasaría si las mujeres hicieran las tareas de los hombres y viceversa. El resultado es el siguiente: ella siendo hombre termina el día sin mayor complicación, pero él siendo mujer no puede más, está cansado y rebasado por las tareas domésticas, lo cual tiene la intención de dejar claro que la organización social por géneros es injusta. En La señora tiene antojos (Madame a des envies, 1906) aborda el embarazo desde un punto de vista femenino, pues visibiliza la gestación, pero también una forma placentera de sobrellevarlo [FIGURAS 12 y 13 ].

\begin{abstract}
Alice Guy, en Madame a des envies (1906) refleja excepcionalmente y con una complicidad gozosa - fuera del capricho histérico-compulsivo con el que habitualmente han sido tratados - los antojos que tiene una mujer embarazada. Su particular visión de estos deseos - llena por otra parte de ternura, ironía y de gran comicidad - propone una noción de la experiencia gestante felizmente egoísta, exenta de toda la construcción ideológica creada por la tecnología patriarcal, que ha conducido a una interesada idealización limitativa y cercenada de la enorme potencialidad de goce también expansivo que en la mayoría de casos se vive con el embarazo. Por otra parte, el propósito del filme de Alice Guy no solo trasciende las limitaciones en torno a cómo se construye el arquetipo mujer-madre sino que, en el orden de la sintaxis fílmica incorpora como pionero uno de los primeros usos legibles dados al primer plano (Selva y Solá, 2002, p. 21).
\end{abstract}

De acuerdo con el propio documental, Alice Guy-Blaché pasó los últimos años de su vida tratando de obtener los créditos por su trabajo, debido a que algunas de sus películas le fueron adjudicadas a su asistente en Gaumont; y sus filmes realizados en Solax, la productora que inició en Estados Unidos, a su exmarido, como si siempre fuera más fácil pensar en ellos como artistas y creadores y no en ellas. Es justo sobre esta idea que gira la película: expone la grandeza de Alice, pero también lo difícil de su reconocimiento en un sistema 
FIGURAS 8, 9 y 10.

Los inventos tecnológicos de Alice Guy-Blaché (Be Natural: The Untold Story of Alice Guy-Blaché, Pamela B. Green, 2018).
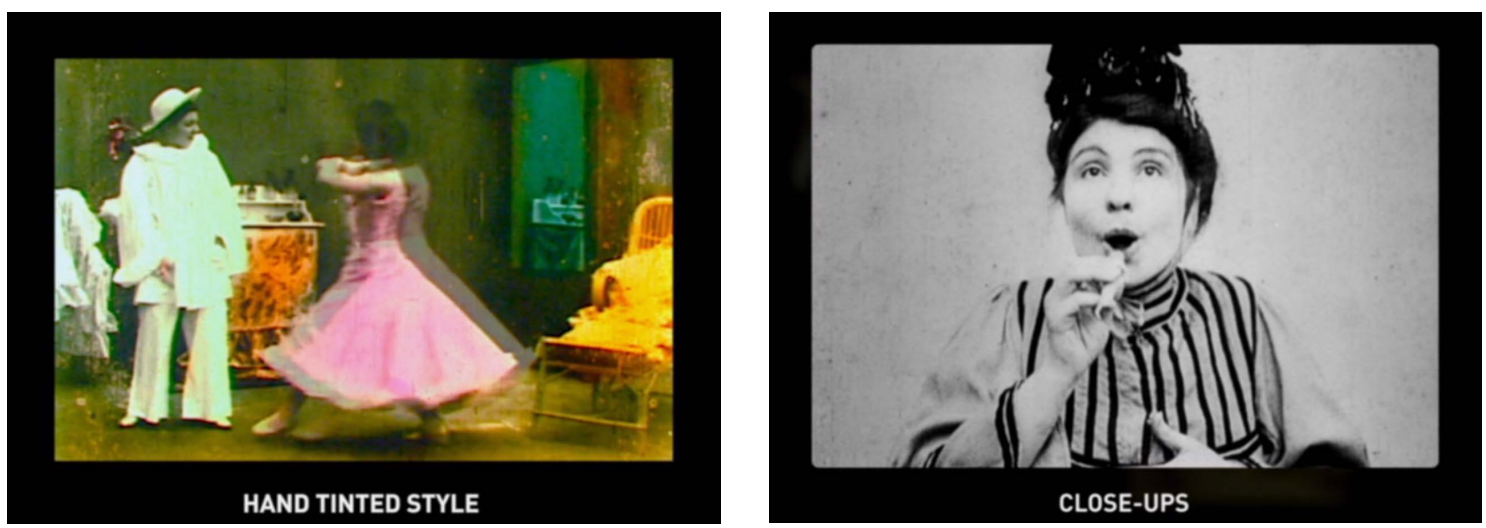

FIGURA 11. Alice Guy-Blaché produjo más filmes en su época que otros de sus compañeros cineastas

Be Natural: The Untold Story of Alice Guy-Blaché, Pamela B. Green, 2018).

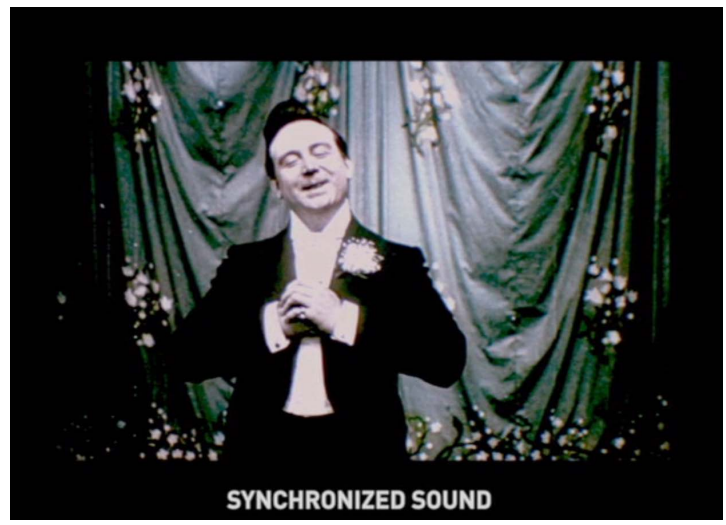

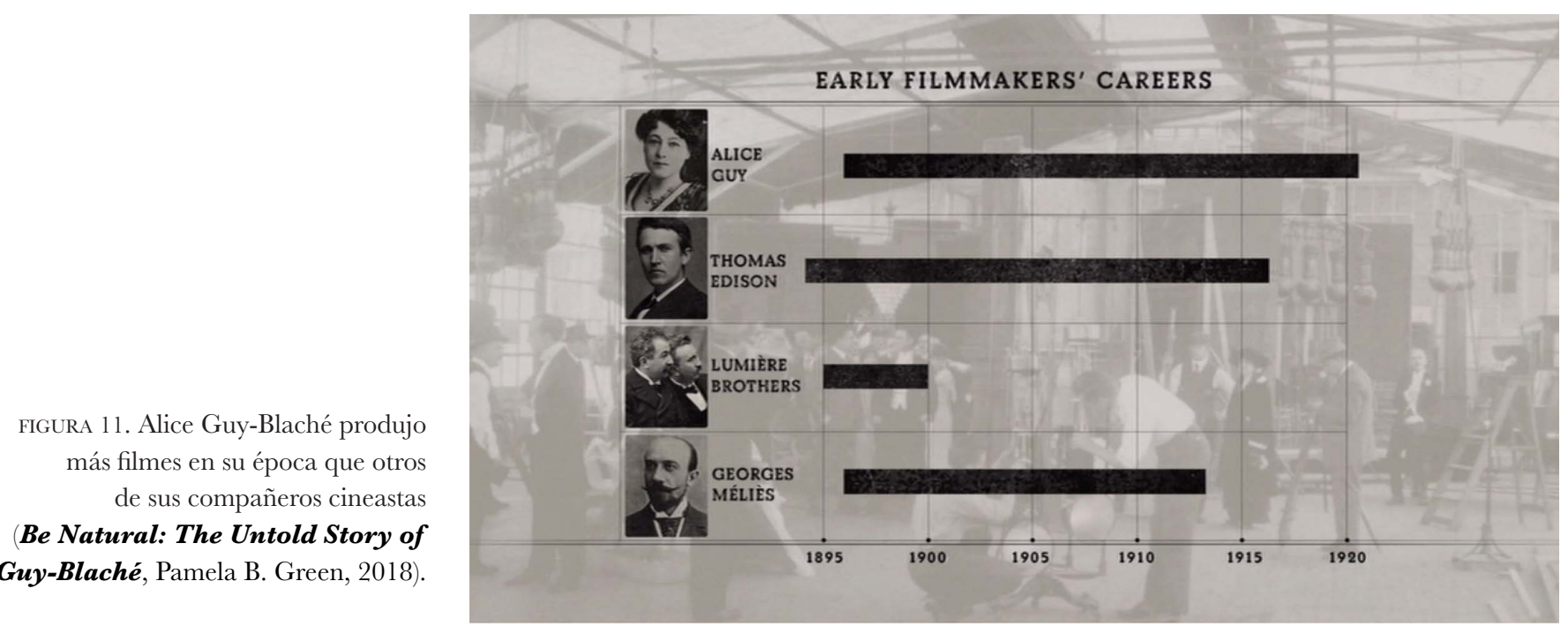



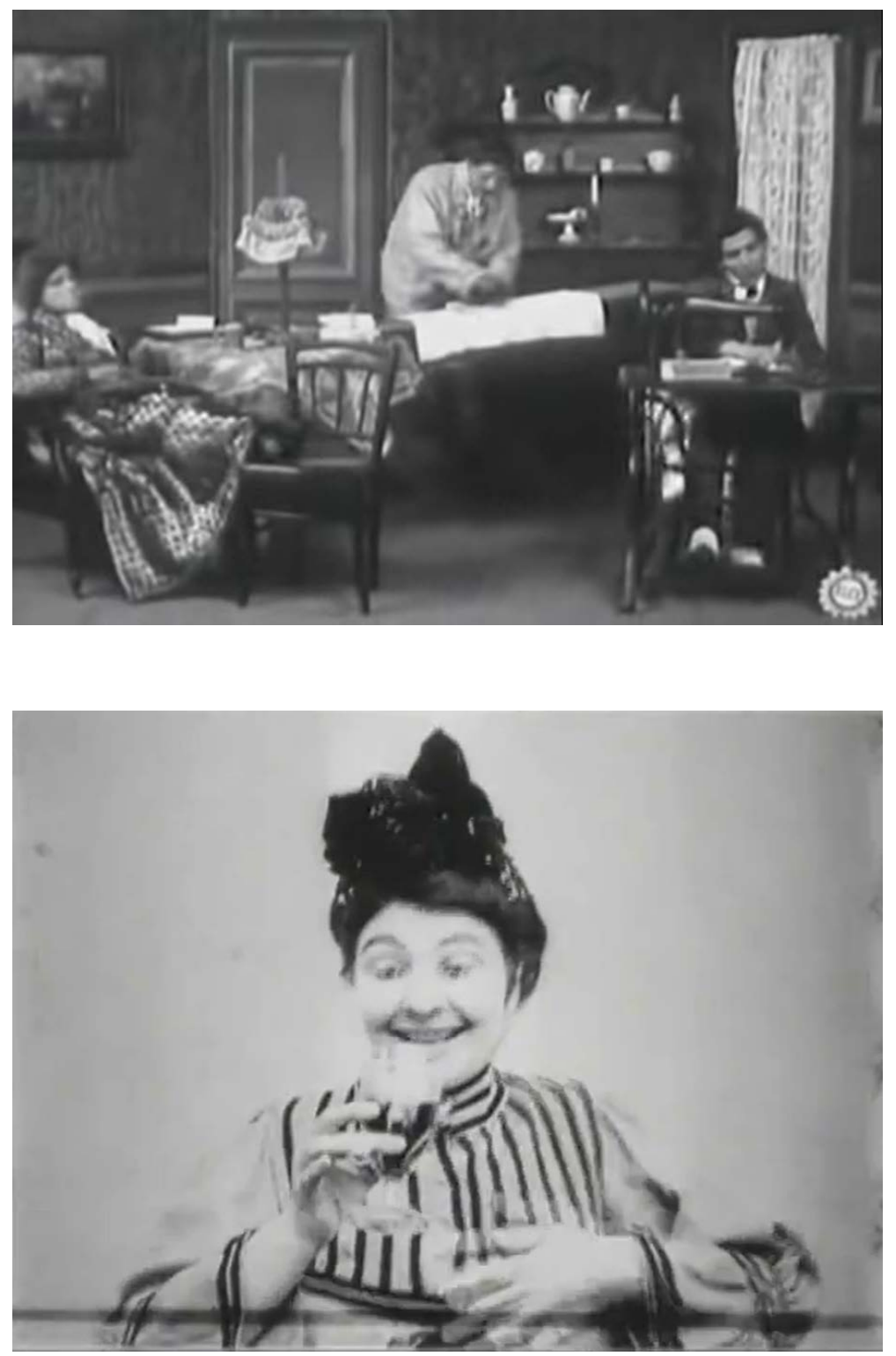

FIGURAS 12 y 13. El interés de Alice Guy-Blaché

por abordar el cine desde lo femenino

(Las consecuencias del feminismo, Les résultats du féminisme, 1906; La señora tiene antojos, Madame a des envies, 1906). 
plenamente patriarcal. La propuesta se suma al feminismo radical, pues deja claro la necesidad de reescribir la historia y demostrar que las mujeres siempre han estado presentes en esta.

\section{EL CAMINO SOÑADO: DEVELANDO LA MENTIRA DEL VIVIERON FELICES PARA SIEMPRE}

El camino soñado, de Angela Schanelec, cuenta la historia de dos mujeres que se separan de sus parejas. La primera transcurre en los años 80 y explica la historia de Theres, una joven alemana que vive en Grecia cantando en los camiones junto a Kenneth, su novio inglés. La segunda, que sucede 30 años después en Berlín, es la historia de Ariane, una actriz de televisión que decide separarse de su marido porque ya no le ama. Ambas son madres y los hijos están cerca de ellas, pero su maternidad no es todo lo que las constituye.

El cine de Angela Schanelec es reconocido como parte del movimiento de la Escuela de Berlín (Berliner Schule), un cine que se ha caracterizado principalmente por la utilización, en contraste, de lugares urbanos con lugares rurales, creando así escenarios que provocan una sensación de ser conocidos y desconocidos a la vez. Sus historias emergen de la cotidianidad sin convertirse en grandes dramas. Los temas de las películas de la Escuela de Berlín parecen siempre ser tratados con frialdad y distancia. En estos filmes el tiempo muerto es habitual y siempre se respira un dejo de melancolía política (Nord, 2007).

Entre los cineastas del movimiento existen algunos puntos de encuentro:

Hay diferencias muy evidentes entre el cine de Angela Schanelec, Christian Petzold o Thomas Arslan, por mencionar a los pioneros del grupo, pero los tres comparten la necesidad de trabajar sobre el mundo contemporáneo, sobre la realidad como materia viva y sobre personajes sin certezas, en situación de tránsito. Es un cine abierto, en el sentido más amplio de la palabra: un cine que no parte de ideas preconcebidas sino que va expresando sus dudas y eventualmente encontrando sus certezas al mismo tiempo que sus personajes (La Escuela de Berlín. El joven cine alemán del siglo XXI, 31 de enero de 2012).

En ese sentido, no se puede leer El camino soñado sin tomar en cuenta el contexto de la Escuela de Berlín y sus características, puesto que este filme hace uso de casi todas ellas. Los lugares urbanos y rurales de la primera historia carecen de referente, la ciudad y el campo no se reconocen como parte de un territorio real, más bien crean la suerte de un mundo imaginario en donde Theres pasea y vive su ruptura. En un jardín que parece más un espacio interior que real, se da cuenta de que algo ya no podrá ser igual con Kenneth y decide irse. Los tiempos muertos son el propio duelo y el espectador acompaña a Theres a decidir y avanzar, pero desde el plano de la emoción y no de la información, como menciona Roger Koza:

Cada tanto no está mal preguntarse por la naturaleza de las emociones en el cine. ¿Por qué una imagen suscita una emoción? En el cine de Schanelec en general y en The Dreamed Path en particular el flujo de emociones es desencadenado por una radicalización de la experiencia sensible. La conmoción más que narrativa es física, y solicita una atención específica (Koza, 2017, parr. 1).

La segunda historia, que parece no tener nada que ver con la primera, también sucede en este aparente tiempo muerto. La escena más representativa — y a la vez la más simbólica en relación a la ruptura - es la de la pareja arreglando su biblioteca; él pregunta qué libros tirar y cuáles guardar, y ella, decidida, elimina algunos títulos. En esta escena doméstica que podría parecer irrelevante se lee el porqué de la separación: el tiempo hace que ciertas ideas, "ciertos libros", ya no sean de interés propio, así de complejo y así de simple. Las personas cambian, evolucionan, la vida parece ser muchas vidas y no solo una única elección [FIGURAs 14 y 15].

Las historias de Theres y de Ariane se pueden leer desde el feminismo plural porque desmenuzan un sentimiento 
muy pocas veces visto y tratado de esta forma en el cine: el desencanto. Si Hollywood se empeñó en representar a las mujeres como objetos de satisfacción masculina, el hecho de filmar el desencanto y luego la separación de las parejas desde la perspectiva femenina es un gesto de liberación absoluto, expresado, además, con tranquilidad, sin escándalos y sin dramas. Ellas simplemente se desencantan y se van. No hay un "vivieron felices para siempre" con sus parejas y este, a su vez, se invierte por un "vivieron libres y tomaron el control de sus decisiones". Además esto se cuenta dentro de contextos distintos, de ahí que las épocas sean tan representativas: no importa cuándo o dónde, lo importante es saber quién eres y qué deseas.

\section{Conclusiones}

Ninguna de estas tres películas está pensada como cine feminista o cine de mujeres, pero todas son protagonizadas por mujeres, de ahí que se pueda pensar en un análisis de este tipo. Cada una de ellas, en la superficie, podría ser ejemplo de un discurso feminista particular: La estafadoras, con su equipo de mujeres ladronas, puede ilustrar la búsqueda del feminismo liberal, es decir, buscar obtener la misma participación que ellos en pantalla; Be Natural: The Untold

Story of Alice Guy-Blaché es un filme documental que en su esfuerzo por visibilizar a la gran Alice, devela cómo desaparecen las mujeres y su obra en el cine, apoyando de esta manera a los discursos sobre feminismo radical que ven la necesidad de denunciar todas estas fallas históricas; El camino soñado, en su afán de contar historias mínimas, permite narrar de manera muy diferente una ruptura en la que quien decide es ella, y no pretende ser dramática sino silenciosa. Esta característica se coloca dentro de los feminismos plurales que comprenden que las mujeres reaccionan de manera distinta a los hombres y que son libres de decidir y marcharse. Estos personajes no son buenos ni malos, son complejos y en ello radica su carácter feminista.

Este texto ha pretendido dejar hablar a los filmes, no a las teorías feministas, con la intención de mostrar tres maneras de visibilizar lo femenino para evidenciar que hay formas diferentes de representar a las mujeres en pantalla y que estas representaciones tienen implicaciones, también distintas, en el debate sobre la igualdad de género. Es un punto de partida para seguir trabajando en la representación de lo femenino y la necesidad de actualizar los discursos feministas en el cine.

Asimismo, estas tres películas también podrían ser un ejemplo de cómo Hollywood, el cine documental y/o el cine de autor aportan diversos discursos sobre la representación de la mujer y, en este mismo sentido, cómo se pueden nutrir las miradas de unos y otros, porque en el cine la igualdad no necesita darse en un género específico o en un tipo de cine particular, sino en todos ellos. 

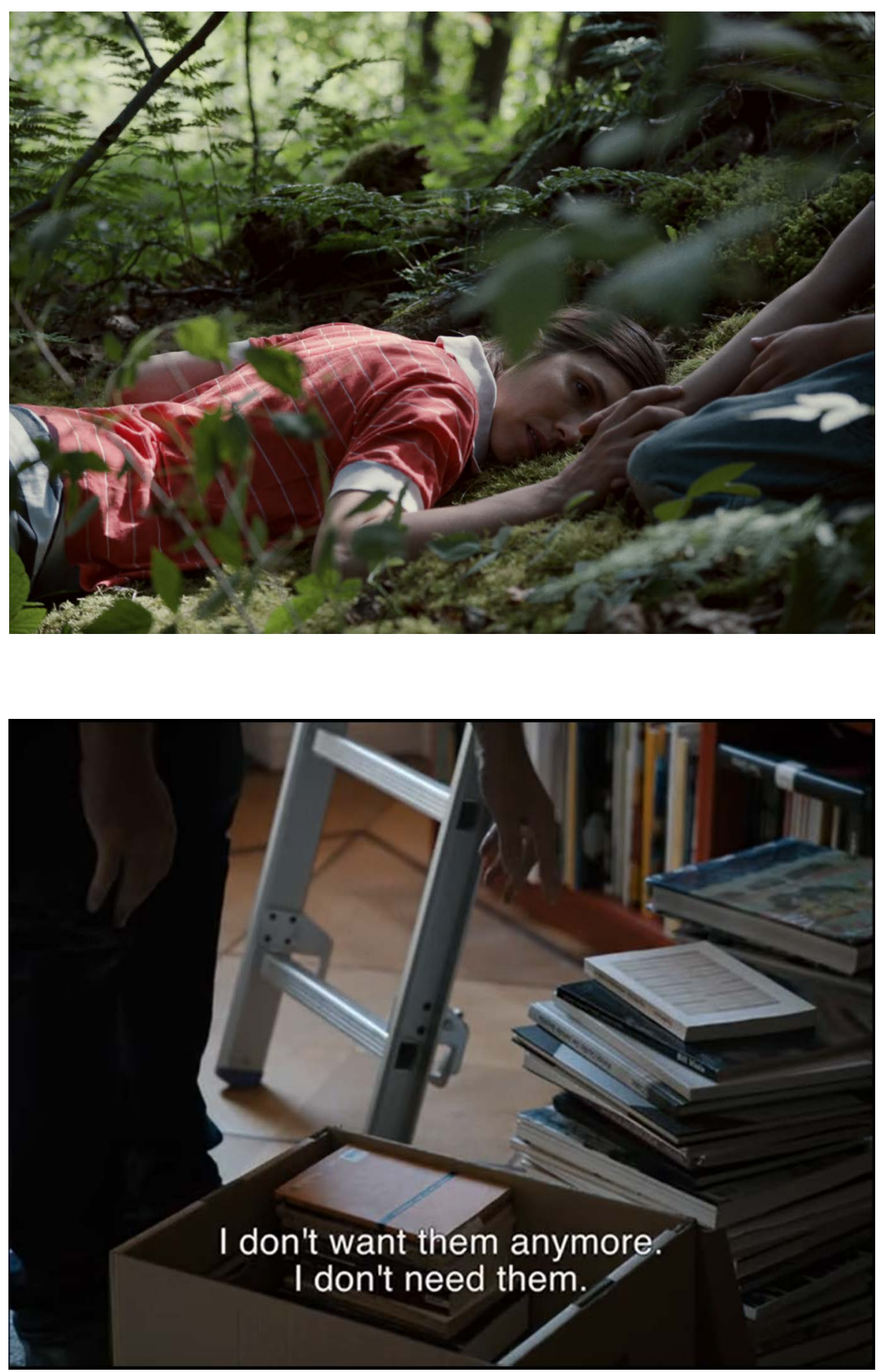

FIGURAS 14 y 15. Los momentos del desencanto (El camino soñado, Der traumhafte Weg,

Angela Schanelec, 2016). 


\section{Bibliografía}

\section{Filmografía}

Association for Women's Rights in Development. (1 de agosto de 2004). Interseccionalidad: una herramienta para la justicia de género y la justicia económica. AWID. Recuperado de https://www.awid.org/es/publicaciones/interseccionalidad-una-herramienta-para-la-justicia-de-genero-y-la-justicia-economica

CubiLlos Almendra, J. (2015). La importancia de la interseccionalidad para la investigación feminista. Oxímora. Revista Internacional de Ética y Política, 7, 119-137. Recuperado de https://revistes.ub.edu/index.php/oximora/article/view/14502

GILA, J. y Guil, A. (1999). La mujer actual en los medios: estereotipos cinematográficos. Comunicar, 12, 83-93. doi: https://doi.org/10.3916/C12-1999-13

Hochschild. A. R. (2003). The Managed Heart. Commercialization of Human Feeling. Berkeley, EE.UU:: University of California Press.

Koza, R. (7 de junio de 2017). Las películas de Angela Schanelec (02): Der traumhafte Weg / The Dreamed Path / El camino soñado. Con los ojos abiertos. Recuperado de http://www.conlosojosabiertos.com/las-peliculas-angela-schanelec-der-traumhafte-weg-the-dreamed-path-camino-sonado/

Kunn, A. (1991). Cine de mujeres. Feminismo y cine. Madrid, España: Cátedra.

La Escuela de Berlín. El joven cine alemán del siglo XXI. (31 de enero de 2012). La Cinemateca Sevilla. Recuperado de https://lacinematecasevilla.wordpress. com/2012/01/31/la-escuela-de-berlin-el-joven-cine-aleman-del-siglo-xxi/

Mulvey, L. (2001). El placer visual y el cine narrativo. En K. Cordero e I. Sáenz (Comps.), Crítica feminista en la teoría e historia del arte (pp. 81-93). Ciudad de México, México: Universidad Iberoamericana.

Nord, G. (7 de julio de 2007). Notas sobre la Berliner Schule (Escuela Berlinesa). Otros Cines. Recuperado de https://www.otroscines.com/nota?idnota=2932

Selva, M. y Solá, A. (2002). Diez años de la Muestra Internacional de Filmes de Mujeres. Barcelona, España: Paidós.

VArela, N. (2008). Feminismo para principiantes. Barcelona, España: Ediciones B.

Green, P. B. (Directora \& Productora) \& Littlewood, C. y Simon, J. (Productoras). (2018). Be Natural: The Untold Story of Alice Guy-Blaché. EE.UU.: Be Natural Productions.

GuY-BlaCHÉ, A. (Directora). (1906). Las consecuencias del feminismo [Les résultats du féminisme]. Francia: Gaumont.

GuY-Blaché, A. (Directora). (1906). La señora tiene antojos [Madame a des envíes]. Francia: Gaumont. 
Ross, G. (Director) \& Ekins, S. y Soderbergh, S. (Productores). (2018). Las estafadoras [Ocean's 8]. EE.UU.: Warner Bros., Village Roadshow Pictures, Smoke House Pictures.

Schanelec, A. (Directora) \& Von Alberti, I. y Schlaich, F. (Productores). (2016). El camino soñado [Der traumhafte Weg]. Alemania: Filmgalerie 451, Tigerlily Films.

Soderbergh, S. (Director) \& Weintraub, J. (Productor). (2001). La gran estafa [Ocean's Eleven]. EE.UU.: Warner Bros., Village Roadshow Pictures.

Fabiola Algalá Anguiano (México) es Doctora en Comunicación Audiovisual por la Universitat Pompeu Fabra de Barcelona. Profesora investigadora del Departamento de Estudios de la Comunicación Social de la Universidad de Guadalajara. Sus principales líneas de investigación son: el análisis cinematográfico, el cine documental y los estudios visuales.

Fanny Gervantes González (México) es egresada de la Licenciatura en Comunicación Pública de la Universidad de Guadalajara. 